\title{
Protective effect of zinc sulfate and continuous/interval training on liver oxidative stress in morphine-withdrawal syndrome in rats
}

\author{
Sahar Hasani ${ }^{1,5}$, Hassan Ghasemi ${ }^{2}$, Akram Ranjbar ${ }^{3}$, Reza Ghahremani ${ }^{4}$, Ali Heidarianpour ${ }^{5}$, Hadis \\ Abotalebian $^{6}$, Alireza Gharib ${ }^{7}$, Nejat Kheiripour ${ }^{6 *}$ iD \\ 1. Student Research Center, Hamadan University of Medical Sciences, Hamadan, Iran \\ 2. Department of Clinical Biochemistry, Abadan School of Medical Sciences, Abadan, Iran \\ 3. Department of Toxicology and Pharmacology, School of Pharmacy, Hamadan University of Medical Sciences, Hamadan, Iran \\ 4. Department of Exercise Physiology, Faculty of Sport Sciences, University of Birjand, Birjand, Iran \\ 5. Department of Exercise Physiology, Faculty of Physical Education and Sport Sciences, Bu-Ali Sina University, Hamadan, Iran \\ 6. Research Center for Biochemistry and Nutrition in Metabolic Diseases, Kashan University of Medical Sciences, Kashan, Iran \\ 7. Neurophysiology Research Center, Hamadan University of Medical Sciences, Hamadan, Iran
}

\section{Abstract}

Introduction: In this study, the effect of zinc sulfate (ZS) supplement and eight-week continuous training (CT) and interval training (IT) on liver oxidative stress of morphine-dependent rats following withdrawal syndrome (WS) were evaluated.

Methods: Seventy Wistar rats were randomly divided into seven groups: control rats, withdrawing rats (WS), withdrawing rats receiving $9 \mathrm{mg} / \mathrm{kg}$ ZS orally (WS+Z), withdrawing rats under $\mathrm{CT}$ (WS+CT), withdrawing rats under IT (WS+IT), withdrawing rats under $C T$ and receiving $9 \mathrm{mg} / \mathrm{kg}$ zinc sulfate $(W S+Z+C T)$, withdrawing rats under IT and receiving $9 \mathrm{mg} / \mathrm{kg}$ zinc sulfate $(\mathrm{WS}+Z+\mathrm{IT})$. Animals were addicted by $0.4 \mathrm{~g} / \mathrm{l}$ morphine sulfate in 21 days. Animals in the training groups ran on a treadmill and received ZS 5 days/week for 8 weeks. At the end of the study, oxidative stress in liver tissue and liver enzymes were measured by spectrophotometric and ELISA methods.

Results: ZS supplement, CT/IT led to decrease DNA damage and malondialdehyde in comparison with morphine group. Also, ZS, CT and IT significantly elevated levels in superoxide dismutase, catalase activity, total antioxidant capacity and thiol groups in the liver of rats in comparison with morphine group. Additionally, it is observed that ZS and CT/IT made a significant reduction in aspartate aminotransferase levels in comparison to the morphine group.

Conclusion: CT/IT with ZS because of its antioxidant effects has the potential to be used for decreased withdrawal syndrome complications.

http://dx.doi.org/10.32598/ppj.24.4.10
Keywords:

Zinc Sulfate;

Continuous Training; Interval Training;

Morphine;

Withdrawal Syndrome;

Liver

\section{* Corresponding author:}

N. Kheiripour

Email:

kheiripour-n@kaums.ac.ir

Tel: +98 (31) 55540021

Received 3 October 2019;

Received in revised form 15

April 2020; Accepted 26 May 2020

\section{Introduction}

Prevalence of drug use disorders is about 31 million people worldwide. WHO has reported, roughly 450,000 people died as a result of drug use in 2015 . 
Opioids continued to cause the most harm, accounting for $76 \%$ of the deaths where drug use disorders were implicated (Liu et al., 1999) Morphine, the main component of opium, is perhaps the oldest drug known to man. Morphine decreases stimulation of pain nervous path neurons by connecting to $\mu$-type receptors. Therefore, it is used as a strong anti-pain largely to relieve severe pain (Gordon et al., 1995). Nevertheless, long-term using of these drugs exerts several adverse side-effects, including addiction, tolerance, respiratory depression, immunosuppression and constipation. Addiction is one of the most important issues in human societies, which not only makes social and behavioral disorders but also impose great financial influencing (Schütz et al., 2018).

Liver is one of the vital body organs that plays a major role in detoxification of the toxic elements and chemical drugs. Liver is considered as a major tissue of morphine biotransformation where morphine exerts several adverse toxic, immunological and oncogenic effects (Salahshoor et al., 2016). Increased liver enzymes including aspartate aminotransferase (AST), alanine aminotransferase (ALT) and alkaline phosphatase (ALP) are reported in laboratory animals after receiving morphine (Salahshoor et al., 2018).

Oxidative stress plays a crucial role in toxic liver damage (Todaka et al., 2005). Studies showed that morphine results in oxidative stress by inducing the generation of reactive oxygen species (Gach et al., 2011). Samarghandian et al. (2014) reported that morphine consumption increased induction of lipid peroxidation and decreased anti-oxidant system's power (the activity of enzymes such as superoxide dismutase [SOD] and catalase [CAT]) which is associated with liver toxicity and damage. Studies showed that morphine is converted to morphinone by morphine-6-dehydrogenase, and after conjugate with glutathione, and removed, which reduces glutathione sources (Nagamatsu et al., 1986).

The antioxidants can protect the liver tissue against oxidative damage. Exercise plays a major role in human health. The beneficial effects of regular exercise and physical activity have been known for a long time. Exercise is part of the treatment of many diseases via induces the antioxidant defense's in several tissues such as liver, heart and kidney (Simioni et al., 2018). In addition, exercise and physical activity have caused increased blood circulation in the liver and accelerated biotransformation and they also decreased liver oxidative toxic stress (Habib et al., 2020; Trefts et al., 2015).

Trace element homeostasis is critical for antioxidant defense systems. Zinc incorporates in the function of more than 300 enzymes. Studies have shown that zinc plays a specific role in biochemical processes such as cell respiration, DNA propagation, maintaining the integrity of cell membrane and reducing free radicals (Stefanidou et al., 2006). Zinc ions defenses against free radicals by competitive role against copper and iron ions that induced producing free radicals during Haber Weiss reaction. Also, animal-based studies have shown that zinc deficiency can make a significant reduction in vitamin $E$ serum levels. Vitamin $E$ is a protective agent against oxidative damage and prohibits lipoproteins oxidation (Eide, 2011).

Zinc deficiency well-documented in opioid consumers (Ciubotariu et al., 2015). However, based on our studies, there is little information regarding the effect of exercise or zinc supplementation on oxidative stress markers in morphine-dependent rats following withdrawal syndrome. Hence, investigating the effect of exercise and zinc supplementation on liver oxidative stress in the opium users could be considerably beneficial for withdrawing the opium. Therefore, in the current study, we assessed the impact of interval/continuous exercise and zinc supplementation on the liver oxidative stress in morphine-dependent rats following withdrawal syndrome.

\section{Materials and methods}

In this experimental study, 70 male Wistar rats $(250 \pm 20 \mathrm{~g})$ were used. Animals were maintained in the animal house with free access to water and food throughout 12:12 hour's light/dark cycle. All ethical considerations were confirmed by the given instructions of Hamadan University of Medical Sciences (IR.UMSHA.REC.1395.195). Animals were randomly categorized into seven groups $(n=10)$ : Group 1: healthy control rats (C); Group 2: withdrawing rats without exercise training and receiving normal saline (WS); Group 3: withdrawing rats receiving $9 \mathrm{mg} / \mathrm{kg}$ zinc sulfate orally $(\mathrm{WS}+Z S)$; Group 4: withdrawing rats under continuous exercise training (WS+CT); Group 5: withdrawing rats under 


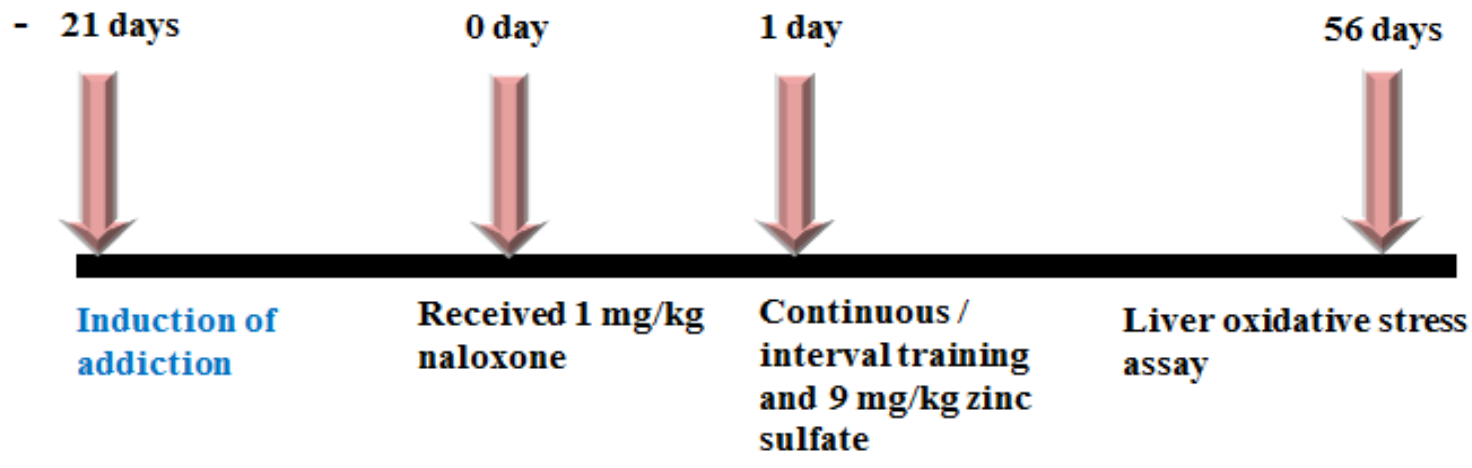

Fig.1. Experimental timeline.

Table 1: Continuous and interval training protocols

\begin{tabular}{ccc}
\hline Week & Continuous group & Interval group \\
\hline 1 & $16(12 \mathrm{~m} / \mathrm{min})$ & $2 \times 8(12 \mathrm{~m} / \mathrm{min})$ \\
\hline 2 & $20(12 \mathrm{~m} / \mathrm{min})$ & $2 \times 10(12 \mathrm{~m} / \mathrm{min})$ \\
\hline 3 & $24(13 \mathrm{~m} / \mathrm{min})$ & $2 \times 12(13 \mathrm{~m} / \mathrm{min})$ \\
\hline 4 & $28(14 \mathrm{~m} / \mathrm{min})$ & $2 \times 14(14 \mathrm{~m} / \mathrm{min})$ \\
\hline 5 & $33(15 \mathrm{~m} / \mathrm{min})$ & $3 \times 11(15 \mathrm{~m} / \mathrm{min})$ \\
\hline 6 & $39(16 \mathrm{~m} / \mathrm{min})$ & $3 \times 13(16 \mathrm{~m} / \mathrm{min})$ \\
\hline 7 & $45(17 \mathrm{~m} / \mathrm{min})$ & $3 \times 15(17 \mathrm{~m} / \mathrm{min})$ \\
\hline 8 & $51(18 \mathrm{~m} / \mathrm{min})$ & $3 \times 17(18 \mathrm{~m} / \mathrm{min})$ \\
\hline
\end{tabular}

interval exercise training (WS+IT); Group 6: withdrawing rats under continuous exercise training receiving $9 \mathrm{mg} / \mathrm{kg}$ zinc sulfate (WS+ZS+CT); Group 7: withdrawing rats under interval exercise training receiving $9 \mathrm{mg} / \mathrm{kg}$ zinc sulfate (WS+ZS+IT).

\section{Addiction}

Animals in morphine-dependent groups were addicted by $0.4 \mathrm{~g} / \mathrm{l}$ morphine sulfate during 21 days. In addition, sucrose $(40 \mathrm{mg} / \mathrm{m})$ was added to drinking water due to the bitter taste of morphine. To ensure that the morphine-induced dependency in the animals, 1-2 rats in each working group received $1 \mathrm{mg} / \mathrm{kg}$ naloxone (Sigma-Aldrich, St. Louis, MO, USA, IP) (Zarrinkalam et al., 2016). After being assured of morphine, they were put on the treadmill for 1 week to get acquainted with the treadmill for 15 minutes at a speed of $13 \mathrm{~m} / \mathrm{s}$. Rats that did so easily were selected as the study groups. Then animals of the training groups performed continuous/interval exercise training and $9 \mathrm{mg} / \mathrm{kg}$ zinc sulfate were orally for five days in a week for 8 weeks.

\section{Continuous training}

In this protocol, rats were exercised for 8 weeks, 5 days/week. Rats had performed the training with
$12 \mathrm{~m} / \mathrm{min}$ for 16 minutes. During 8 weeks, the training speed and duration were gradually increased and they exercised for 51 minutes with $18 \mathrm{~m} / \mathrm{min}$ on the treadmill (Table 1).

\section{Interval training}

The training was performed in a multi-stage phases for interval group and active recovery was considered. Training was followed with $12 \mathrm{~m} / \mathrm{min}$ with two 8-minute phases, which was increased to three 17-minute phases with $18 \mathrm{~m} / \mathrm{min}$ (Table 1) (Shabkhiz et al., 2008). At the end of treatments, rats were anaesthetized with ketamine $(50 \mathrm{mg} / \mathrm{kg}, \mathrm{IP})$ and immediately, their livers were maintained in $-80^{\circ} \mathrm{C}$. Also, the serum was collected and maintained for measuring liver enzymes activity (Fig .1).

\section{Tissue collection and processing}

Liver tissues of rats were excised and rinsed with icecold saline and grounded into a fine powder using liquid nitrogen. The homogenate was resuspended in ice cold lysis buffer (10mM HEPES, $10 \mathrm{mM} \mathrm{KCl}$, $1.5 \mathrm{mM} \mathrm{MgCl} 2,1 \mathrm{mM}$ EDTA, $0.2 \%$ triton $\mathrm{X} 100,0.5 \mathrm{mM}$ dithiothreitol, protease inhibitor cocktail, $\mathrm{pH}$ 7.9) and incubated on ice for $20 \mathrm{~min}$. The tissue homogenates were vortexes and centrifuged $\left(14,000 \mathrm{~g} ; 10 \mathrm{~min} ; 4^{\circ} \mathrm{C}\right)$, 
and the supernatants were retained for analysis (Goli et al., 2019).

\section{Assay of total protein}

Total protein concentration in tissue homogenates was assessed by the Bradford method using bovine serum albumin as the standard (Kruger, 1994).

\section{Assay of lipid peroxidation}

Malondialdehyde (MDA) were measured used the thio-barbitoric acid method (TBA) to assess lipid peroxidation, which its maximum absorption of the pink complex read TBA+MDA in the wavelength by $532 \mathrm{~nm}$. In this method the calibration curve of tetraethoxypropane standard solutions was used to determine the concentrations of TBA+MDA adducts in samples (Shateri et al., 2019).

\section{Assay of total antioxidant capacity (TAC)}

In order to evaluate TAC, we used ferric reducing ability of plasma (FRAP) method, in which it was added to major samples of FRAP containing 2, 4, 6tripiperidyltriazine (TPTZ 6, 4,2), and maximum absorption of blue complex+Fe ${ }^{2+}$ TPTZ was read as $593 \mathrm{~nm}$ in the wavelength (Ranjbar et al., 2018).

\section{Assay of total thiol groups}

Total thiol groups were evaluated as the other indicator of oxidative stress status. Thiol groups are sensitive to oxidative damages and their decrement is an important indicator for oxidative stress. It was used Hu-calorimetric method of DTNB (2.2-dithionitrobenzoic acid, known as Ellman) in order to evaluate these parameters. So, maximum absorption was read as $412 \mathrm{~nm}$ in the wavelength (Rahimi et al., 2018).

\section{Assay of DNA damage}

The amount of DNA damage (8-OHdG) superoxide dismutase and catalase were assessed by ELISA kit according to its protocol.

\section{Assay of activity of liver aminotransferase enzyme}

Serum levels of ALT and AST were assayed by Pars Azmoon kit.

\section{Statistical analysis}

The SPSS software, version 23.0 (SPSS Inc.,
Chicago, IL, U.S.A) and GraphPad Prism version 6.0 (GraphPad Software, San Diego, CA, USA) were applied for statistical analysis. All data analyzed by one-way analyses of variance (ANOVA) followed by Tukey's post hoc test. Results were considered significantly different if $P<0.05$.

\section{Results}

\section{SOD activity}

The results of measuring liver tissue SOD activity in the studied groups are shown in Figure 2. SOD activity in a healthy control group was significantly more than withdrawing syndrome control groups and withdrawing groups with continuous training $(P<0.05)$. Conversely, SOD activity level in withdrawing control group was significantly lower than withdrawing groups with interval training, continuous training and zinc sulphate and interval training with zinc sulphate $(P<0.05)$.

\section{CAT enzyme activity}

The results of measuring liver tissue CAT enzyme activity in the studied groups are illustrated in Figure 3. In contrast, the CAT activity level in a healthy

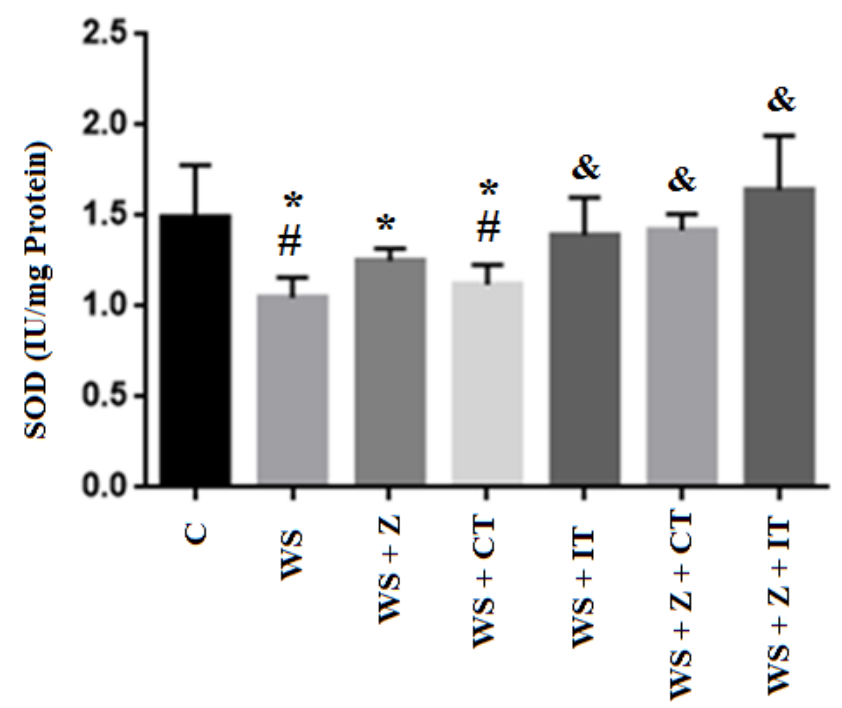

Fig.2. Comparison of superoxide dismutase (SOD) activity in the liver tissue of studied groups. Data is represented as mean $\pm S D$. Healthy control (C), withdrawing syndrome (WS), zinc sulfate (Z), continuous training (CT), interval training (IT). "Significant statistical difference with healthy control group, \&significant statistical difference in comparison with WS group $(P<0.05)$. "Significant statistical difference in comparison with $\mathrm{WS}+\mathrm{Z}+\mathrm{IT}$ group $(P<0.05)$. There was no significant difference between the other groups. 


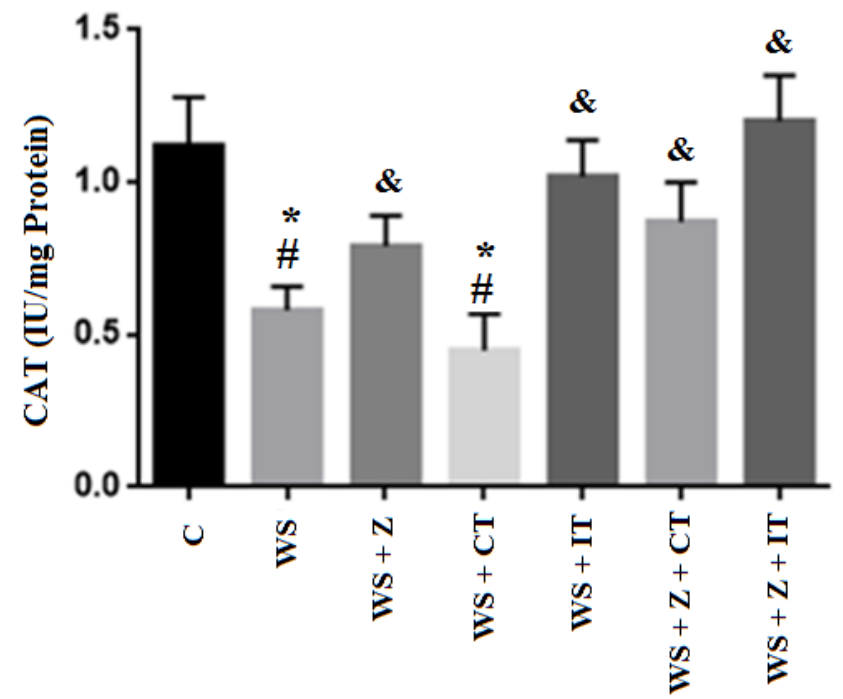

Fig.3. Comparison of catalase (CAT) enzyme activity in the liver tissue of studied groups. Data is represented as mean $\pm S D$. Healthy control (C), withdrawing syndrome (WS), zinc sulfate (Z), continuous training (CT), interval training (IT). "Significant statistical difference with healthy control group, \&significant statistical difference in comparison with WS group $(P<0.05)$. 'Significant statistical difference in comparison with WS+Z+IT and WS+IT group $(P<0.05)$. There was no significant difference between the other groups.

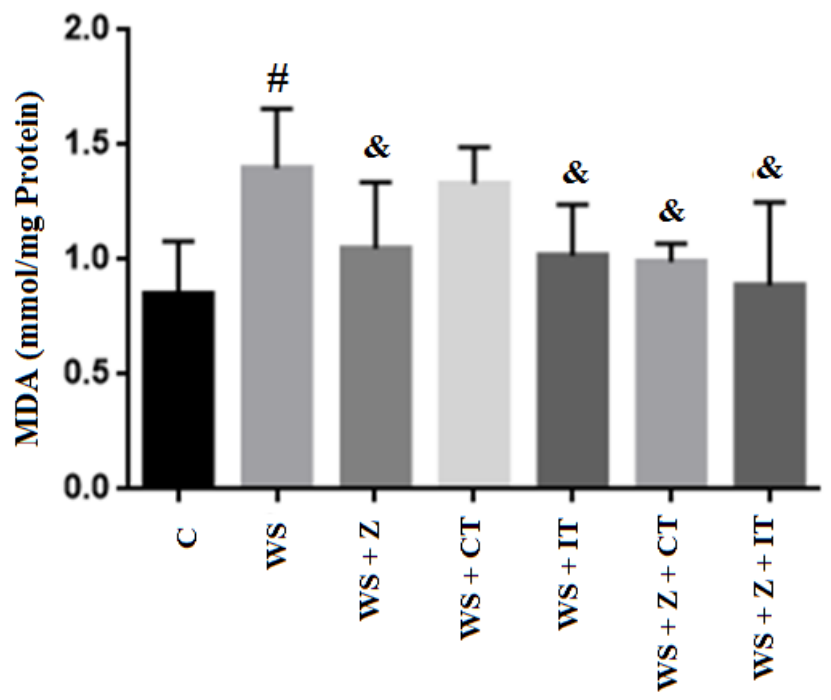

Fig.4. Comparison of lipid peroxidation level (MDA) in the liver tissue of studied groups. Data represented is as mean $\pm S D$. Healthy control (C), withdrawing syndrome (WS), zinc sulfate (Z), continuous training (CT), interval training (IT). "Significant statistical difference with healthy control group, \&significant statistical difference in comparison with WS group $(P<0.05)$. There was no significant difference between the other groups.

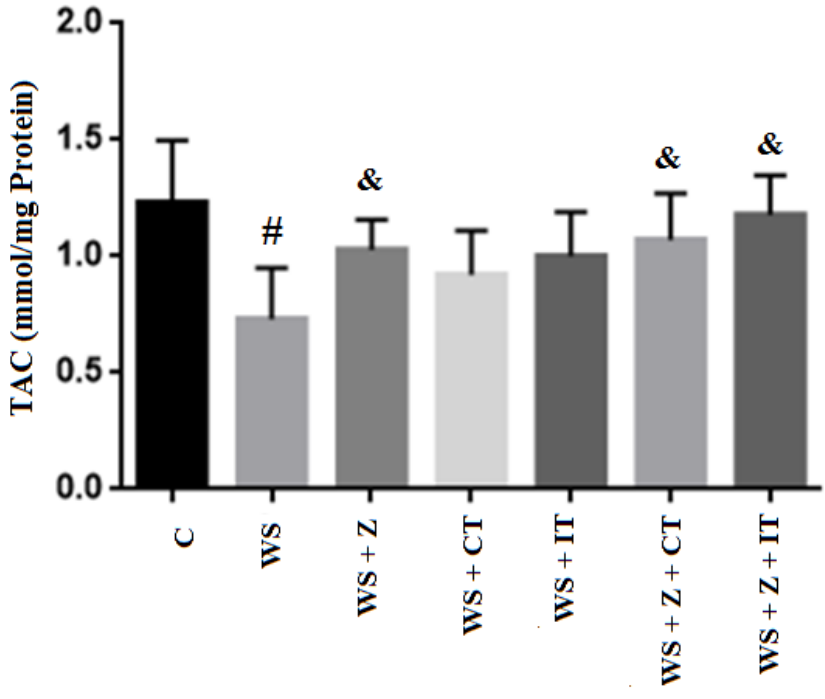

Fig.5. Comparison of total antioxidant capacity (TAC) in liver tissue of the studied groups. Data is represented as mean $\pm S D$. Healthy control (C), withdrawing syndrome (WS), zinc sulfate (Z), continuous training (CT), interval training (IT). "Significant statistical difference with healthy control group, \&significant statistical difference in comparison with WS group $(P<0.05)$. There was no significant difference between the other groups.

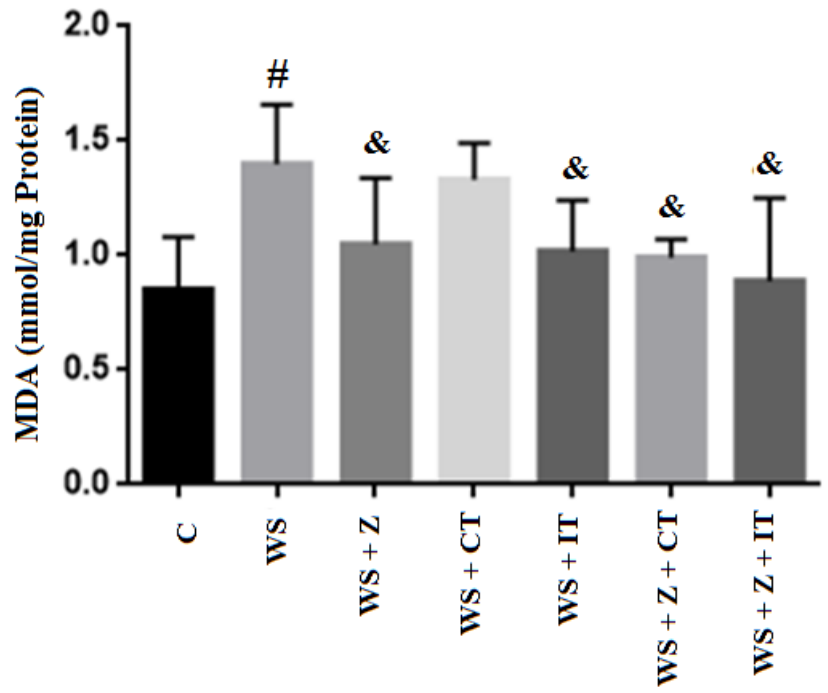

Fig.6. Comparison of alanine aminotransferase (ALT) activity level in the studied groups. Data is represent as mean $\pm S D$. Healthy control (C), withdrawing syndrome (WS), zinc sulfate (Z), continuous training (CT), interval training (IT). There was no significant difference between groups. 


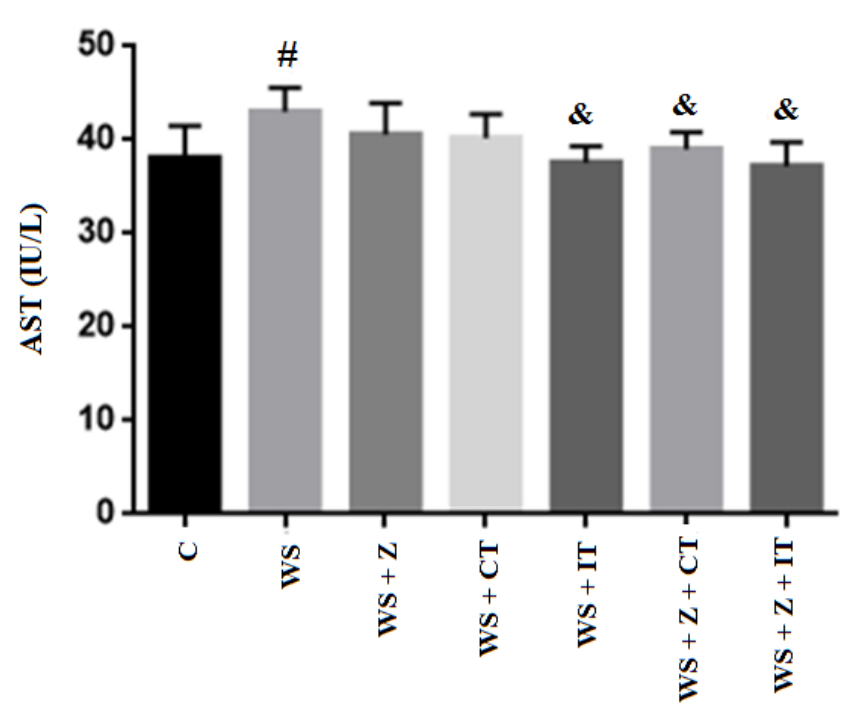

Fig.7. Comparison of aspartate aminotransferase (AST) activity in the studied groups. Data is represent as Mean $\pm S D$. Healthy control (C), withdrawing syndrome (WS), zinc sulfate (Z), continuous training (CT), interval training (IT). "Significant statistical difference with healthy control group, \& significant statistical difference in comparison with WS group $(P<0.001)$. There was no significant difference between the other groups.

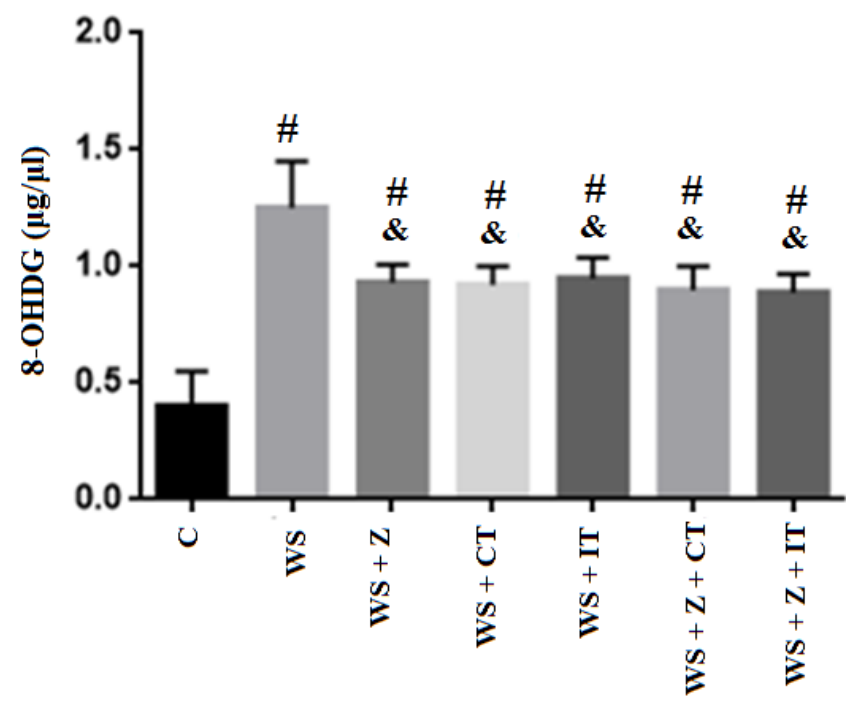

Fig.8. Comparison of DNA damage level (8-OHdG) in the studied groups. Data is represent as mean \pm SD. Healthy control (C), withdrawing syndrome (WS), zinc sulfate $(Z)$, continuous training (CT), interval training (IT). "Significant statistical difference with healthy control group, \& significant statistical difference in comparison with WS group $(P<0.05)$. There was no significant difference between the other groups.

control group was significantly more than withdrawing syndrome control group and withdrawing group with continuous training $(P<0.05)$. Conversely, the CAT activity level in withdrawing control group was significantly lower than withdrawing groups with interval training, receiving zinc sulfate, continuous training, continuous training with zinc sulfate and interval training with zinc sulfate $(P<0.05)$.

\section{Lipid peroxidation measurement}

The results of measuring lipid peroxidation level (MDA) are illustrated in Figure 4. In contrast, lipid peroxidation level in withdrawing control group was significantly more than other studied groups $(P<0.05)$. Significant statistical difference in other groups did not detect $(P>0.05)$.

\section{TAC measurement}

According to the results shown in Figure 5, TAC in withdrawing control group was significantly lower than the healthy control group $(P<0.05)$. Oral zinc sulfate, continuous exercise training with zinc sulfate and interval exercise training with zinc sulfate improved in TAC in comparison with withdrawing control group $(P<0.05)$.

\section{ALT and AST activity}

The results of ALT activity are illustrated in Figure 6. According to these results, the studied groups did not show any significant statistical differences ( $P>0.05)$. In contrast, AST activity in withdrawing control group was significantly more than healthy control, interval training, interval training with zinc sulfate and continuous training with zinc sulfate $(P<0.001$, Fig. 7$)$.

\section{Assessing DNA damage level (8-OHdG)}

Results of DNA damage level according to $8-\mathrm{OHdG}$ in the liver of studied groups are illustrated in Figure 8. Level of $8-\mathrm{OHdG}$ in the healthy control group in comparison with withdrawing syndrome control group was significantly lower $(P<0.001)$. On the other hand, 8-OHdG in withdrawing syndrome control group was significantly more than other treated withdrawing groups $(P<0.001)$.

\section{Discussion}

Opioids are considered as the most important antipain drugs. Morphine is an opioid analgesic drug and the main psychoactive chemical in opium. Oxidative stress and apoptosis are the main mechanisms of morphine-induced cytotoxicity. Morphine increases oxidative stress through two pathways: 1- increasing oxygen reactive species and 2- inhibiting antioxidant 
system performance in the cell (Skrabalova et al., 2013). In the present study, results indicated that oxidative stress was increased in the treated group with morphine, which is similar to the results obtained from other studies. Zhang et al. (2004) reported that morphine induces oxidative stress markers in the liver of rats, such as $8-\mathrm{OHdG}, \mathrm{MDA}$ and reducing the activity of anti-oxidants enzyme including SOD, catalase and glutathione peroxidase. In addition, treating with ascorbic acid as an antioxidant substance leads to reduce oxidative stress conditions in the liver of rats. Also, it was reported that morphine decreases anti-oxidant and glutathione enzymes in the intestine and liver of rats, which is consistent with our study results (Nagamatsu et al., 1983; Salehi et al., 2018; Sumathi and Niranjali Devaraj, 2009). Studies have shown that morphine increases dopamine and xanthine oxide metabolism, which cause increased oxygen reactive species. In addition, morphine usage increased the risk of lipid peroxidation level and then liver damages due to disturbance of antioxidant/oxidant balance (Lurie et al., 1995).

In order to eliminate oxygen reactive species, biologic antioxidant enzymes such as SOD, catalase, glutathione peroxidase and non-enzymatic antioxidants react with oxygen reactive species (Samarghandian et al., 2014). In the present study, results showed that lipid peroxidation was increased and CAT and SOD antioxidant enzymes were decreased in the rats received morphine. On the other hand, treating with continuous/interval training with zinc sulfate improved the antioxidant system (SOD and CAT) and then, it decreased oxidative stress in the liver tissue. Similarly, Mallikarjuna et al. (2009) indicated that regular exercise training significantly reversed the increase MDA and decreases GSH and ascorbic acid induced by ethanol drinking. Also it was reported that endurance, resistance and concurrent exercise significantly normalized oxidative stress and the morphological changes of the intestine in withdrawal rats (Salehi et al., 2018). It is reported that continuous and interval training decreased oxidative damage in erythrocytes of the studied humans (Yunus et al., 2018). Various mechanisms are provided for describing antioxidant enzyme responses to exercise training. It is well described that following exercise training especially severe endurance training, free radical production increases. Subsequently, MDA as an indicator of lipid peroxidation increases, then cell defensive system such as antioxidant enzymes induce and activate in order to meet produced oxidative stress (Jahani et al., 2010)

It was shown that swimming training decreased oxidative damage, fat mass and protein oxidation in high-fat diet animals. Also, it has improved their metabolism characteristics in comparison with the control group (Zacarias et al., 2017). Following exercise training, it seems that cell defensive system attempts to provide the balance and/or enhancement of antioxidant enzymes against oxidative stress. Interestingly, our findings is in agreement with previous studies which showed that, continuous and interval training and zinc sulfate decrease oxidative stress level in morphine-dependent rats in withdrawing syndrome.

Liver injury causes changes in liver enzyme levels and secretion soluble cytosolic enzymes into the circulation. Aminotransferase (ALT, AST and ALP), bilirubin (total and direct) are the most sensitive and the most widely used for the detection of liver injury (Khazaei et al., 2016). Releasing these enzymes from liver cytosol to blood is reported during toxicities with morphine (Atici et al., 2005). This study also demonstrated that serum ALT and AST levels decreased after treatment with continuous and interval training and zinc sulfate.

It was reported in the study by Samarghandian et al. (2014) that the levels of liver enzymes AST and ALT in the serum of treated rats with morphine were significantly more than the healthy control group which is consistent with the results of the present study. Also, Nabizadeh Haghighi and Shabani (2016) reported that exercise training significant reduction in AST and ALT enzymes activity in fatty liver patients. Significant decreasing of AST and ALT enzymes due to exercise training are probably related to the increased liver oxidation rate, decreased activity of lipogenic enzymes and decreased liver fatty acids (Shamsoddini et al., 2015).

Finally, this study demonstrated that, the effect of zinc with continuous and interval training on the provided stress in morphine-dependent rats was considered as synergistic. Various mechanisms were mentioned for zinc anti-oxidant effects. Zinc increases the synthesis of metallothionein -cysteinerich protein - which acts as a free radical inhibitor. 
Also, zinc is incorporated in the structure of the most body enzymes, for example, SOD which is considered as the major antioxidant enzyme (Stefanidou et al., 2006). Another important effect of zinc is its competitive role against iron and copper ions. Free ions of iron and copper convert $\mathrm{H}_{2} \mathrm{O}_{2}$ to free radicals of $\mathrm{OH}$ through Haber-Weiss reaction and increase oxidative stress through this reaction. Zinc, as a competing ion in this interaction, restricts that and reduces oxidative agents. Also, animal studies have shown that zinc deficiency may significantly decrease vitamin $E$ serum level. Vitamin $E$ is a protective factor against oxidative damage and inhibits lipoproteins oxidation (Bunk et al., 1989; Eide, 2011). Lack of histological tests, gene expression and molecular tests and short study period are some of the limitations of the present study. On the other hand, the simultaneous use of zinc supplements and continuous/interval training on oxidative stress of liver tissue was performed for the first time in morphinewithdrawal model, which is one of the strengths of the study. Also, different factors of oxidative stress, enzymatic activity in tissue were measured.

\section{Conclusion}

Our findings pointed out the risk of increased oxidative stress and hepatic damage due to morphine. Although morphine is reported to be effective in pain management, their toxic effects should be kept in mind during usage. Results showed that interval/continuous training with zinc sulfate supplementation decreased oxidative stress in morphine withdrawing syndrome rats. Based on the results of this study, we conclude that $\mathrm{IT}, \mathrm{ZS}+\mathrm{CT}$ or $Z S+I T$ exert similar effects on liver oxidative stress. However, further studies are needed in order to examine and verify the molecular pathways underlying the effects of continuous and interval training with zinc sulfate supplementation in the liver tissue of morphine-dependent animal models.

\section{Acknowledgments}

The study was funded by Hamadan University of Medical Sciences, Hamadan, Iran (Thesis Number: 9505052574).

\section{Conflict of interest}

The authors have declared no conflicts of interest.

\section{References}

Atici S, Cinel I, Cinel L, Doruk N, Eskandari G, Oral U. Liver and kidney toxicity in chronic use of opioids: an experimental long term treatment model. J Biosci 2005; 30: 245-52. https://doi.org/10.1007/BF02703705

Bunk MJ, Dnistrian AM, Schwartz MK, Rivlin RS. Dietary zinc deficiency decreases plasma concentrations of vitamin E. Proc Soc Exp Biol Med 1989; 190: 379-84. https://doi.org/10.3181/00379727-190-42876

Ciubotariu D, Ghiciuc CM, Lupușoru CE. Zinc involvement in opioid addiction and analgesia--should zinc supplementation be recommended for opioid-treated persons? Subst Abuse Treat Prev Policy 2015; 10: 29. https://doi.org/10.1186/s13011-015-0025-2

Eide DJ. The oxidative stress of zinc deficiency. Metallomics 2011; 3: 1124-9. https://doi.org/10.1039/ c1mt00064k

Gach K, Wyrębska A, Fichna J, Janecka A. The role of morphine in regulation of cancer cell growth. Naunyn Schmiedebergs Arch Pharmacol 2011; 384: 221-30. https://doi.org/10.1007/s00210-011-0672-4

Goli F, Karimi J, Khodadadi I, Tayebinia H, Kheiripour N, Hashemnia M, et al. Silymarin attenuates ELMO-1 and KIM-1 expression and oxidative stress in the kidney of rats with type 2 diabetes. Ind J Clin Biochem 2019; 34: 172-9. https://doi.org/10.1007/s12291-018-0735-0

Gordon NC, Gear RW, Heller PH, Paul S, Miaskowski C, Levine JD. Enhancement of morphine analgesia by the GABAB agonist baclofen. Neuroscience 1995; 69: 3459. https://doi.org/10.1016/0306-4522(95)00335-G

Habib M, Bhatti S, ur Rehman S, Javed N, Shahbaz Aslam M, Shahzad N, et al. Hepatoprotective role of swimming against arsenic induced oxidative stress in mice. J. King Saud Univ Sci 2020; 32: 822-7. https://doi.org/10.1016/j.jksus.2019.02.011

Jahani GR, Firoozrai M, Matin Homaee $\mathrm{HH}$, Tarverdizadeh $B$, Azarbayjani M, Mo vaseghi GR, et al. The effect of continuous and regular exercise on erytrocyte antioxidative enzymes activity and stress oxidative in young soccer players. Razi J Med Sci 2010; 17: 22-32.

Khazaei M, Karimi J, Sheikh N, Goodarzi MT, Saidijam M, Khodadadi I, et al. Effects of resveratrol on receptor for advanced glycation end products (RAGE) expression and oxidative stress in the liver of rats with type 2 diabetes. Phytother Res 2016; 30: 66-71. https://doi.org/ 10.1002/ptr.5501

Kruger NJ. The Bradford method for protein quantitation. Methods Mol Biol 1994; 32: 9-15. https://doi.org/ 10.1385/0-89603-268-X:9

Liu N, Rockhold RW, Ho IK. Electrical stimulation of nucleus paragigantocellularis induces opioid withdrawal-like behaviors in the rat. Pharmacol Biochem Behav 1999; 62: 263-71. https://doi.org/10.1016/S00913057(98)00164-6

Lurie E, Soloviova A, Alyabieva T, Kaplun A, Panchenko L, Shvets V. Effect of novel aromatic derivative of GABA on lipid peroxidation in chronically morphinized rats. Biochem Mol Biol Int 1995; 36: 13-9. 
Mallikarjuna K, Nishanth K, Hou CW, Kuo $\mathrm{CH}$, Sathyavelu Reddy K. Effect of exercise training on ethanol-induced oxidative damage in aged rats. Alcohol 2009; 43: 59-64. https://doi.org/10.1016/j.alcohol.2008.09.003

Nabizadeh Haghighi A, Shabani R. Comparing effects of medication therapy and exercise training with diet on liver enzyme levels and liver sonography in patients with non-alcoholic fatty liver disease (NAFLD). J Fasa Univ Med Sci 2016; 5: 488-500.

Nagamatsu K, Ohno Y, Ikebuchi H, Takahashi A, Terao T, Takanaka A. Morphine metabolism in isolated rat hepatocytes and its implications for hepatotoxicity. Biochem Pharmacol 1986; 35: 3543-8. https://doi.org/ 10.1016/0006-2952(86)90624-6

Nagamatsu KU, Kido YA, Terao TA, Ishida TA, Toki SA. Studies on the mechanism of covalent binding of morphine metabolites to proteins in mouse. Drug Metab Dispos 1983; 11: 190-4.

Rahimi R, Karimi J, Khodadadi I, Tayebinia H, Kheiripour N, Hashemnia $\mathrm{M}$, et al. Silymarin ameliorates expression of urotensin II (U-II) and its receptor (UTR) and attenuates toxic oxidative stress in the heart of rats with type 2 diabetes. Biomed Pharmacother 2018; 101: 24450. https://doi.org/10.1016/j.biopha.2018.02.075

Ranjbar A, Firozian F, Soleimani Asl S, Ghasemi H, Taheri Azandariani M, Larki A, et al. Nitrosative DNA damage after sub-chronic exposure to silver nanoparticle induces stress nephrotoxicity in rat kidney. Toxin Rev 2018; 37: 327-33. https://doi.org/10.1080/15569543. 2017.1386685

Salahshoor MR, Khashiadeh M, Roshankhah S, Kakabaraei S, Jalili C. Protective effect of crocin on liver toxicity induced by morphine. Res Pharm Sci 2016; 11 : 120-129.

Salahshoor MR, Vahabi A, Roshankhah S, Darehdori AS, Jalili $C$. The effects of thymoquinone against morphineinduced damages on male mice liver. Int $\mathrm{J}$ Prev Med 2018; 9: 8. https://doi.org/10.4103/ijpvm.IJPVM_144_16

Salehi I, Zarrinkalam E, Mirzaei F, Oshaghi EA, Ranjbar K, Asl SS. Effects of resistance, endurance, and concurrent exercise on oxidative stress markers and the histological changes of intestine after morphine withdrawal in rats. Avicenna $\mathrm{J}$ Med Biochem 2018; 6: 44-9. https://doi.org/10.15171/ajmb.2018.10

Samarghandian S, Afshari R, Farkhondeh T. Effect of longterm treatment of morphine on enzymes, oxidative stress indices and antioxidant status in male rat liver. Int J Clin Exp Med 2014; 7: 1449-53.

Schütz CG, Ramírez-Vizcaya $S$, Froese T. The clinical concept of opioid addiction since 1877: still wanting after all these years. Front Psychiatry 2018; 9: 508. https://doi.org/10.3389/fpsyt.2018.00508

Shabkhiz F, Ravasi A, Hassan Z, Taghikhani M, Razav T. The effect of aerobic continuous and interval training and detraining on some indexes of the cellular immune system in female wistar rats. Sport Sci 2008; 1: 17-26.

Shamsoddini A, Sobhani V, Ghamar Chehreh M E, Alavian
S M, Zaree A. Effect of aerobic and resistance exercise training on liver enzymes and hepatic fat in Iranian men with nonalcoholic fatty liver disease. Hepat Mon 2015; 15: e31434. https://doi.org/10.5812/hepatmon.31434

Shateri H, Ranjbar A, Kheiripour N, Ghasemi H, Pourfarjam Y, Habibitabar E, et al. Tempol improves oxidant/antioxidant parameters in testicular tissues of diabetic rats. Life Sci 2019; 221: 65-71. https://doi.org/ 10.1016/j.Ifs.2019.02.016

Simioni C, Zauli G, Martelli AM, Vitale M, Sacchetti G, Gonelli $A$, et al. Oxidative stress: role of physical exercise and antioxidant nutraceuticals in adulthood and aging. Oncotarget 2018; 9: 17181-98. https://doi.org/10.18632/oncotarget.24729

Skrabalova J, Drastichova Z, Novotny J. Morphine as a potential oxidative stress-causing agent. Mini Rev Org Chem 2013; 10: 367-72. https://doi.org/10.2174/ 1570193X113106660031

Stefanidou M, Maravelias C, Dona A, Spiliopoulou C. Zinc: a multipurpose trace element. Arch Toxicol 2006; 80: 1 9. https://doi.org/10.1007/s00204-005-0009-5

Sumathi T, Niranjali Devaraj S. Effect of Bacopa monniera on liver and kidney toxicity in chronic use of opioids. Phytomedicine 2009; 16: 897-903. https://doi.org/ 10.1016/j.phymed.2009.03.005

Todaka T, Ishida T, Kita H, Narimatsu S, Yamano S. Bioactivation of morphine in human liver: isolation and identification of morphinone, a toxic metabolite. Biol Pharm Bull 2005; 28: 1275-80. https://doi.org/10.1248/ bpb.28.1275

Trefts E, Williams AS, Wasserman DH. Exercise and the regulation of hepatic metabolism. Prog Mol Biol Transl Sci 2015; 135: 203-225. https://doi.org/10.1016/ bs.pmbts.2015.07.010

Yunus M, Wahjuni ES, Fadhli NR. A comparative study of effect of interval and continuous training toward oxidative stress level, antioxidant enzyme capacity, and resistance of erythrocyte membrane. Advances in Social Science, Education and Humanities Research. Journal 2018; 278. https://doi.org/10.2991/yishpesscois- 18.2018 .60

Zacarias AC, Barbosa MA, Guerra-Sa R, De Castro UG, Bezerra FS, de Lima WG, et al. Swimming training induces liver adaptations to oxidative stress and insulin sensitivity in rats submitted to high-fat diet. Redox Rep 2017; 22: 515-23. https://doi.org/10.1080/13510002. 2017.1315513

Zarrinkalam E, Heidarianpour A, Salehi I, Ranjbar K, Komaki A. Effects of endurance, resistance, and concurrent exercise on learning and memory after morphine withdrawal in rats. Life Sci 2016; 157: 19-24. https://doi.org/10.1016/j.Ifs.2016.05.034

Zhang YT, Zheng QS, Pan J, Zheng RL. Oxidative damage of biomolecules in mouse liver induced by morphine and protected by antioxidants. Basic Clin Pharmacol Toxicol 2004; 95: 53-8. https://doi.org/10.1111/j.17427843.2004.950202.x 